\title{
THE EFFECT OF TOPICAL APPLICATION OF STRONTIUM ON BOND STRENGTH IN ORTHODONTICS. (IN VITRO STUDY)
}

\author{
Maha A. Ahmed ${ }^{1}$, Mohammed G. Elshal ${ }^{2}$ and Wael M. Refai ${ }^{3}$.
}

\section{Abstract}

Objective: to evaluate the effects of topical application of strontium on bond strength in orthodontics in vitro by using Instron universal testing machine. Materials and Methods: forty eight bovine enamel specimens were randomly allocated to four groups $(n=12)$. Specimens of group I were not demineralized and were not pretreated, but served as controls. The other specimens were demineralized by using Featherstone $p \mathcal{H}$ cycling technique to form artificial carious lesions. Samples from group II were only demineralized. The other samples were pretreated with strontium chloride solution(Srcl $\left.C_{2}\right)$ for 5 minutes. Teeth in groups III were treated with $\mathrm{Srcl}_{2}$ solution before acid-etching. Teeth in groups IV were treated with $\mathrm{Srcl}_{2}$ after acid-etching. The brackets were then 6onded. The brackets' SBS was measured and the adhesive remnant was assessed using adhesive remnant index (ARI). Analyses were done for SBS values between the four groups using One-Way ANOVA test followed by Post Hoc Tukey's analysis between each two groups .Fisher's exact test was used to evaluate differences in ARI scores between the groups. Results: srcl $_{2}$ treated group before acid etching )showed the highest mean SBS value when compared to other groups (Mean $\pm S \mathcal{D}$ $=24.7 \pm 7.4 \mathcal{M P a}$ ). There was insignificant difference between the four groups as regarding ARI scores $(p=0.406)$. Conclusion: The topical application of $\mathrm{srCl}_{2}$ did not compromise the bond strength of orthodontic brackets to demineralized bovine enamel.

Keywords : Shear bond strength; Brackets; Demineralized enamel.

\section{Introduction;}

The highest debonding rates of orthodontic brackets occur when the brackets had been stressed by mechanical and thermal impacts. ${ }^{(\mathbf{1})}$ In addition in later stages of orthodontic treatment, enamel demineralization adjacent to brackets is an undesired but frequent event and is a matter of concern for the orthodontist. If debonding happens, further demineralization can be expected . When rebonding is carried out, it seems advisable to stabilize and protect the first enamel lesions before reapplication of brackets. ${ }^{(2)}$ The bond strength of bonded orthodontic brackets should be sufficient to withstand orthodontic forces applied during treatment. The ideal orthodontic adhesive should have adequate bond strength. ${ }^{(3)}$ Reynolds mentioned 5.9-7.8 $\mathrm{MPa}$ resistances are sufficient to withstand masticatory force. ${ }^{(4)}$

Administration of topical agents containing fluoride or casein phosphopeptide-amorphous calcium phosphate (CPP-ACP), maintenance of oral hygiene, and dietary control have been suggested as mechanisms to control the formation of enamel lesions during

1.Demonstrator in department of orthodontics, Faculty of Dentistry, Minia University.

2 .lecturer in department of orthodontics, Faculty of Dentistry, Minia University.

3.Professor and head of department of orthodontics, Faculty of Dentistry, Minia University. 
fixed-appliance treatment. ${ }^{(5)}$ During the last years many researches gave a great part of interest, the role of trace elements other than fluoride. One of the elements that had attracted attention was strontium $\left(\mathrm{Sr}^{2+}\right) .{ }^{(6)}$ Strontium chloride was the first bioactive material added to toothpaste for sealing dentinal tubules approximately 50 years ago. ${ }^{(7)}$ It has been reported that strontium chloride acts through the precipitation of particles on the dental surface, preventing the movement of fluids. ${ }^{(8)}$ The strontium salts can replace the calcium in hydroxyapatite due to the chemical similarity of these elements, favoring tissue remineralization and sealing open dentinal tubules. ${ }^{(9)}$

The current study aimed to study the effects of topical application of strontium chloride solution on shear bond strength of orthodontic brackets to demineralized enamel ,compared its effect before and after acid etching procedure and evaluated facture mode of adhesive used to bond orthodontic brackets to demineralized enamel surface

\section{Materials and Methods :}

Forty eight bovine permanent mandibular central incisors teeth were collected from freshly sacrificed cows. The criteria for selecting the teeth were the following :freshly and fully erupted permanent incisors ,free from caries, cracks or developmental defects. The teeth were cleaned with a scaler to remove soft tissue remnants and callus and were stored in distilled water ${ }^{(\mathbf{1 0})}$ at $4 \mathrm{c}^{\mathrm{o}}$ until the time of the experiment. The teeth were embedded in self-curing acrylic resin in cylindrical molds $(16 \mathrm{~mm}$ diameter).
The daily $\mathrm{pH}$ cycling procedure included a demineralization period of 6 hours and a remineralization period of 16 hours. Each crown was individually immersed in $40 \mathrm{~mL}$ of a demineralization solution (Phthalate buffer SDFCL, $29034 \mathrm{LO5}$,sd fine-chem limited ,industrial estate, worli road, Mumbai)at $\mathrm{pH} 4.3$ for 6 hours (from 9 $\mathrm{AM}$ to $3 \mathrm{PM}$ ) at $37 \mathrm{C}^{\circ}$ in water bath. At the end of the demineralization period the specimens were rinsed with deionized water then individually immersed in 20 $\mathrm{ml}$ of the remineralization solution (phosphate buffer :SDFCL, 29039L05 ,sd fine-chem limited ,industrial estate , worli road, Mumbai )at $37 \mathrm{C}^{\circ}$ overnight 16 hours (from $4 \mathrm{PM}$ to $8 \mathrm{AM}$ ) to simulate the remineralization stage of the caries process at $\mathrm{pH}$ 7.0. This cycling procedure was repeated daily for 10 days. The solution was daily changed to keep the $\mathrm{pH}$ constant. All teeth were then removed from the solutions and were randomly allocated into groups II through IV .

The teeth were prepared according to one of the following surface treatment procedures:

Group I(control):No enamel pretreatment was performed in this group .The enamel surfaces of intact teeth were etched with $37 \%$ phosphoric acid gel(Meta etchant, meta Biomed Europe $\mathrm{GmbH}$, Germany) for 30 seconds, rinsed with water for 30 seconds and dried with an oil-free air source for 10 seconds until frosty white appearance was obtained . The bonding process was carried out according to manufacturer's instructions and guidelines. A thin layer of sealant(light bond, Reliance ortho 
prod.Inc.Itasca,IL60143 U.S.A ) was applied on the etched surface, and light cured adhesive was applied to the base of brackets and the brackets were positioned on the center of the buccal surfaces ,pressed firmly against the tooth and the excess adhesive around the brackets was removed with scaler and light cured with a LED curing unit with light intensity of $1000 \mathrm{~mW} / \mathrm{cm}^{2}$ for 10 seconds each direction (mesial, distal, occlusal, gingival)according to manufacture instructions.

Group II (demineralized/control): brackets were directly bonded to demineralized enamel and the same bracket bonding procedure was used that was described for group I.

\section{Preparation of $\mathbf{S r c l}_{2}$ solution:}

According to AL Anni et al (11), preparation of different $\mathrm{srcl}_{2}$ solutions with different concentrations the following has to be carried out

A. For $50 \mathrm{mmol} / \mathrm{L}$ :dissolving 13.25 $\mathrm{gm}, \mathrm{SrCl}_{2} \cdot 6 \mathrm{H}_{2} \mathrm{O}$.

B. For $100 \mathrm{mmol} / \mathrm{L}$ : dissolving $26.50 \mathrm{gm}$ $\mathrm{SrCl}_{2} \cdot 6 \mathrm{H}_{2} \mathrm{O}$.

C. For $150 \mathrm{mmol} / \mathrm{L}$ : dissolving $39.75 \mathrm{gm}$ $\mathrm{SrCl} 2.6 \mathrm{H}_{2} \mathrm{O}$.

Group III (demineralized/SrCl $\mathbf{S r}_{\mathbf{2}}$ before etching): strontium chloride solution was applied on the enamel surface of demineralized teeth by brushing for $5 \mathrm{~min}$,left undisturbed for $30 \mathrm{~min}$, rinsed, dried and then acid etched as group I. The same bracket bonding procedure was used as described for group I.

Group IV (demineralized/ $\mathbf{S r C l}_{2}$ after etching) :The enamel surfaces of demineralized teeth were first acidetched with $37 \%$ phosphoric acid gel for 30 seconds ,rinsed with water for 30 seconds and dried with an oil-free air source for 10 seconds until frosty white appearance was obtained. Strontium chloride solution was then applied on the enamel surface for $5 \mathrm{~min}$ and left undisturbed for $30 \mathrm{~min}$. The same bracket bonding procedure was used that was described for group I. The teeth were then stored in distilled water at $37 \mathrm{C}^{\circ}$ in water bath for 48 hours before shear bond strength testing.

Debonding procedure(shear bond strength test) :The teeth were secured in lower jaw of the machine and bracket base was paralleled to the direction of shear force. Continuous shear force was applied as close as possible tooth/bracket interface with sharp chisel attached to the end of instron testing machine(cat.NO:2710-115 ,instron ,USA.)at cross head speed of 0.5 $\mathrm{mm} / \mathrm{min}$ until bracket detached and maximum load necessary to debond the bracket was recorded. The force required to remove the brackets was measured in Newton's(N)and Shear bond strength $(\mathrm{SBS})\left(1 \mathrm{MPa}=1 \mathrm{~N} / \mathrm{mm}^{2}\right)$ was then calculated by dividing the force values by the bracket base area $\left(12.6 \mathrm{~mm}^{2}\right)$.

Fracture Analysis: An optical stereomicroscope (BX 60 ,Olympus, ,Japan )with 15X magnification attached to camera (EOS650D, Cannon ,Japan ) was used to determine where the failure occurred and the extent of remaining adhesive on the enamel.

Adhesive remnant index (ARI) scores at the failure area were recorded in accordance with the study by Artun and Bergland. (12) The remnant adhesive on the enamel surface was coded by one investigator who was blinded to group 
allocations. Any adhesive remaining after bracket removal was assessed with the adhesive remnant index. Failures were ranked from zero to three as follows: 0 , no adhesive remained on the tooth; 1,less than half of the adhesive remained on the tooth; 2,more than half of the adhesive remained on the tooth; 3 all of the adhesive remained on the tooth, with a distinct impression of the bracket mesh.

Statistical methods All statistical analyses were performed using the Statistical Package for SPSS for software version 25. Distribution of the data was done by Shapiro Wilk test. The data were found to be normally distributed and there was homogeneity of variance among the groups. Thus, the statistical evaluation was performed using parametric tests (one-way ANOVA, followed by Tukey's post-hoc test). The means, standard deviations and minimum and maximum values were also calculated for each group. Fisher's exact test was used to determine significant differences among the ARI scores from the 4 groups. The level of significance was taken at $(\mathrm{P}$ value < 0.05).

\section{Results}

According to one -way ANOVA ,there was significant difference in shear bond strength values among different groups $(\mathrm{P}<0.001)$. The group III ( $\mathrm{rrcl}_{2}$ treated group before acid etching ) showed the highest mean SBS value when compared to other groups (Mean \pm $\mathrm{SD}=24.7 \pm 7.4 \mathrm{MPa})$. The group IV
( $\mathrm{srcl}_{2}$ treated group after acid etching) showed lowest mean SBS value when compared to others group (Mean $\pm \mathrm{SD}=$ $10.8 \pm 4.2 \mathrm{MPa}$ ). SBS of the group III showed high value (Mean \pm SD $=24.7 \pm 7.4 \mathrm{MPa})$ when compared to group $\mathrm{I}($ Mean $\pm \mathrm{SD}=15.3 \pm 6.1 \mathrm{MPa})$. The mean shear bond strength of the group IV ( srcl2treated group after acid etching)( Mean $\pm \mathrm{SD}=10.8 \pm 4.2 \mathrm{MPa}$ ) showed low value when compared to mean shear bond strength of group $\mathrm{I}($ Mean $\pm \mathrm{SD}=15.3 \pm 6.1 \mathrm{MPa})$. this decrease was insignificant $(\mathrm{P}=0.096)$. The mean shear bond strength of the group II(demineralization without pretreatments) (Mean \pm SD $=19.3 \pm 7.5$ )showed high value when compared to group I ( Mean \pm SD 15.3 \pm 6.1 .) but this increase was insignificant $(P=0.135)$. The results of one -way ANOVA and Post Hoc Tukey's tests were summarized in table(1).

The Results of Fisher's exact test indicated that there was insignificant difference between the four groups as regarding ARI scores $(\mathrm{p}=0.406)$. In group I there was greater frequency of ARI scores of 1 . In group IV, there was higher frequency of ARI scores of 0 ,Indicating adhesive failure of resin (failure between resin and enamel ).In group II,III there was higher frequency of ARI scores 1,2 indicating cohesive failure of the resin (failure within the resin ). The results were summarized in table(2) 


\begin{tabular}{|c|c|c|c|c|c|c|}
\hline & & $\begin{array}{l}\text { Group I } \\
\text { (Control) }\end{array}$ & $\begin{array}{l}\text { Group II } \\
\text { (Demineralizat } \\
\text { ion) }\end{array}$ & $\begin{array}{l}\text { Group } \\
\text { III(srcl2* } \\
* \text { before } \\
\text { acid } \\
\text { etching ) }\end{array}$ & $\begin{array}{l}\text { Group } \\
\text { IV(srcl2 } \\
\text { after acid } \\
\text { etching) }\end{array}$ & $P$ value \\
\hline & & $\mathrm{N}=12$ & $\mathrm{~N}=12$ & $\mathrm{~N}=12$ & $\mathrm{~N}=12$ & \\
\hline $\begin{array}{l}\text { Shear bond } \\
\text { strength(SB } \\
\text { S) }\end{array}$ & $\begin{array}{l}\text { Range } \\
\text { Mean } \pm \\
S D\end{array}$ & $\begin{array}{l}(7.6-28.4) \\
15.3 \pm 6.1\end{array}$ & $\begin{array}{l}(9.9-36.6) \\
19.3 \pm 7.5\end{array}$ & $\begin{array}{l}(14-35.8) \\
24.7 \pm 7.4\end{array}$ & $\begin{array}{l}(4.4-17.8) \\
10.8 \pm 4.2\end{array}$ & $<0.001 *$ \\
\hline \multicolumn{7}{|l|}{$\overline{P \text { value }}$} \\
\hline oup I & & & 0.135 & $0.011 *$ & 0.096 & \\
\hline Group II & & & & 0.298 & $0.002 *$ & \\
\hline Group III & & & & & $<0.001 *$ & \\
\hline
\end{tabular}

Table (1) showing Mean, standard deviation , minimum , maximum values of Shear bond strength in mega Pascal and results of One-Way ANOVA test comparing shear bond strength between the four groups followed by post hoc LSD test between each two groups:
*Significant level at $\mathbf{P}$ value $<0.05$. **Srcl 2 (strontium chloride )

\begin{tabular}{|c|c|c|c|c|c|c|}
\hline & & $\begin{array}{l}\text { Group } \\
\text { I }(\text { control })\end{array}$ & $\begin{array}{l}\text { Group } \\
\text { II(demineraliz } \\
\text { ation) }\end{array}$ & $\begin{array}{l}\text { Group } \\
\text { III(srcl2 } \\
\text { before acid } \\
\text { etching ) }\end{array}$ & $\begin{array}{l}\text { Group } \\
\text { IV }(\text { srl2 } \\
\text { after } \\
\text { acid } \\
\text { etching })\end{array}$ & \multirow[t]{2}{*}{$P$ value } \\
\hline & & $\mathrm{N}=12$ & $\mathrm{~N}=12$ & $\mathrm{~N}=12$ & $\mathrm{~N}=12$ & \\
\hline Score & $\begin{array}{l}\text { Score 0 } \\
\text { Score 1 } \\
\text { Score } 2 \\
\text { Score } 3 \\
\end{array}$ & $\begin{array}{l}3(25 \%) \\
7(58.3 \%) \\
2(16.7 \%) \\
0(0 \%)\end{array}$ & $\begin{array}{l}3(25 \%) \\
5(41.7 \%) \\
4(33.3 \%) \\
0(0 \%)\end{array}$ & $\begin{array}{l}2(16.7 \%) \\
5(41.7 \%) \\
5(41.7 \%) \\
0(0 \%) \\
\end{array}$ & $\begin{array}{l}6(50 \%) \\
4(33.3 \%) \\
1(8.3 \%) \\
1(8.3 \%) \\
\end{array}$ & 0.406 \\
\hline \multicolumn{6}{|l|}{$P$ value } & \\
\hline \multicolumn{2}{|l|}{ oup I } & & 0.863 & 0.556 & 0.434 & \\
\hline \multicolumn{2}{|c|}{ Group II } & & & 1 & 0.328 & \\
\hline \multicolumn{2}{|c|}{ Group III } & & & & 0.123 & \\
\hline
\end{tabular}


Table (2)Frequency distribution of Adhesive Remnant Index (ARI)*and results of Fishers Exact test between groups ,Significant level at $P$ value < 0.05

- $\quad * A R I$ Scores $=0=$ no adhesive left on the enamel.1 $=$ Less than $50 \%$ of adhesive left on the enamel.2= More than $50 \%$ of adhesive left on the enamel. 3= All adhesives left on the enamel.

\section{Discussion}

Rebonding brackets is a common procedure during orthodontic treatment. Because of the high debonding rates of orthodontic brackets resulting from mechanical and thermal stresses, or because orthodontists need to change the position of brackets. ${ }^{(13,14)}$ White spot lesions may be found on the buccal surface of teeth during rebonding. This would lead the orthodontist to being concerned about the adequacy of the bonding procedure to these surfaces. Several studies have investigated the influence of mouthwashes and other materials used for caries prevention enamel and remineralization on the SBS of orthodontic brackets. the current invitro study evaluated the effect of topical application of $\mathrm{srcl}_{2}$ solution on SBS of orthodontic brackets to demineralized bovine enamel, compared its effect before and after acid etching and asessed the facture mode of adhesive used to bond orthodontic brackets to demineralized bovine enamel.

In the current study, the shear bond strength of orthodontic brackets was tested on demineralized bovine enamel by instron testing machine.
Demineralization of the enamel was conducted using the protocol described by Featherstone $\mathrm{pH}$ cycling model. ${ }^{(15)}$ The Featherstone $\mathrm{pH}$ cycling model has been shown to correlate with the findings from human clinical trials and advocated their $\mathrm{pH}$ cycling method as a well-established laboratory cycling. Bovine teeth were used in the current study because bovine enamel has been reported to be a reliable substitute for human enamel in bonding studies, with no statistically significant difference in enamel-bonding value. ${ }^{(16,17)}$ Bovine teeth have a relatively large flat surface, higher porosity which allows a faster diffusion of ions to the demineralized area. Additionally, the artificial caries lesions produced from bovine teeth have a mineral distribution and structure that resembles lesions produced from human teeth both for enamel and dentin.

Maxillary incisors standard edge wise brackets were used in the current study, because of their flat bases, thus ensuring optimal adaptation to the tooth surface. It should be noted that when brackets are more curved mismatch between the curvature of the bracket base and the tooth surface will be possible. This mismatch will affect the stress distribution between the adhesive cement and the tooth surface.

Distilled water was used as storage medium in the current study according to the results of previous study that evaluated the influence of four storage solutions on bovine enamel it was found that the water is the most popular storage solution, which caused the smallest changes in enamel substrate over time in 
comparison to saline, thymol, artificial saliva solutions. ${ }^{(18)}$

The time of application The $\mathrm{srcl}_{2}$ solution on demineralized enamel and the time elapsed between its application and bracket bonding was chosen to simulate the clinical conditions in which bracket re bonding is necessary in the same session .Five minutes application of $\mathrm{Srcl}_{2}$ solution was determined according to previous study of Alencar et al ,in which the application of $10 \%$ strontium chloride on the bleached enamel for 5 minutes after polishing in each bleaching session, minimized the deleterious effects of hydrogen peroxide, promoted a significant increase in hardness and a decrease in surface roughness. ${ }^{(19)}$

The results of the current study indicated that the shear bond strength of orthodontic brackets was significantly impacted by the application of $\mathrm{srcl}_{2}$ as well as by time of acid etching. SBS of $\mathrm{srcl}_{2}$ treated groups before acid etching showed the highest increase among the others groups. but this increase was insignificant in comparison to demineralized group ( $\mathrm{p}$ value $=0.298$ ), while application of $\mathrm{Srcl}_{2}$ after acid etching resulted in lower SBS value than when applied before acid etching .but this decrease was insignificant in comparison to control group (p value $=0.096$ ).

The highest SBS obtained in $\mathrm{srcl}_{2}$ treated groups may be explained by the fact that Strontium has an atomic radius slightly larger than calcium and readily substitutes for calcium in minerals. ${ }^{(20)}$ It is possible that the polishing of demineralized enamel before application of $\mathrm{srcl}_{2}$ and application of $\mathrm{srcl}_{2}$ on the surface of demineralized enamel by brushing might be have removed the demineralized soft enamel layer and exposed the under hard enamel layer and the strontium precipitates plugging into the Ca-deficient site of hydroxyapatite, improved the crystallinity of hydroxyapaptite increased hardness of enamel . this might be increased the roughness of enamel and increased the surface area for adhesive bonding .this might be attributed to higher bond strength to demineralized enamel and this explanation was agreed with Xiaojunet al, that microscopically assessed and compared enamel treated with CPP-ACP and untreated enamel after etching and found that treated and etched enamel had a rougher surface than untreated enamel. (21)

The decrease shear bond strength of $\mathrm{scl}_{2}$ treated groups after acid etching when compared to other groups might be explained ,as stated in previous study by Yin-Lin Wang, et $\mathrm{al}^{(\mathbf{2 2})}$, when the enamel was acidified after the release of calcium ions and phosphate ions, therefore the surface of enamel was negatively charged. This negatively-charged enamel surface could attract a great amount of positively-charged strontium ions onto the enamel surface; this layer of positively-charged strontium ions was called the Stern layer that in turn reduce the erosive potential of acidic solution and achieve the protective effect on the enamel as well as the absence of rinsing step after application of $\mathrm{srcl}_{2}$ solution in current study. This might be attributed to decrease the bond strength to enamel by preventing the complete penetration of resin to enamel and decreasing number of 
resin tags. This decrease was insignificant when compared to control group and the SBS value of this group remained above the clinical acceptable range between 5.9 and $7.8 \mathrm{MPa}$ as recorded by Reynolds range. ${ }^{(23)}$

According to the ARI scores, there was insignificant difference among the groups. The group II and group III showed higher frequency of score 1, 2 indicating that failures were cohesive (failures within the resin ). The group I and group IV showed higher frequency of score 1, 0 respectively, most of the composite resin was left on the bracket when the brackets were debonded. This means that the bond failure occurred purely or primarily at the adhesiveenamel interface indicating the adhesive failure of the resin (meaning that the bond strength between bracket and resin was stronger than that between resin and enamel).Enamel fractures have been occurred in two samples one in group II, and other in group III.

\section{Conclusions}

- The topical application of $\mathrm{srcl}_{2}$ did not compromise the bond strength of orthodontic brackets to demineralized bovine enamel.

- SBS of srcl $_{2}$ treated groups before acid etching showed the highest increase among the others groups, but this increase was insignificant in comparison to demineralized group ( $p$ value $=0.298$ ) - Application of Srcl2 after acid etching resulted in lower SBS value than when applied before acid etching .but this decrease was insignificant in comparison to control group .(p value $=0.096)$ and still within the clinical acceptable range between 5.9 and 7.8 MPa as recorded by Reynolds range

- The SBS of demineralized group showed higher value when compared to control but this increase was insignificant.

- According to the ARI scores, there was insignificant difference among the groups. The group II and group III showed higher frequency of score 1, 2 indicating that failures were cohesive (failures within the resin) The group I and group IV showed higher frequency of score 1,0 respectively, indicating the adhesive failure of the resin (meaning that the bond strength between bracket and resin was stronger than that between resin and enamel).

\section{References ;}

1.De Saeytijd C, Carels CE and Lesaffre E: An evaluation of a light-curing composite for bracket placement. Eur J Orthod .(1994);16:541-545

2. Oesterle LJ and Shellhart WC: Effect of aging on the shear bond strength of orthodontic brackets. Am J Orthod Dentofacial Orthop.( 2008);133:716720.

3.Sharma S, Tandon P, Nagar A, Singh GP, Singh A, Chugh VK et al. A comparison of shear bond strength of orthodontic brackets bonded with four different orthodontic adhesives J Orthod Sci (2014);3:29- 33

4. Reynolds IR: A review of direct orthodontic bonding. $\mathrm{Br} \mathrm{J}$ Orthod (1975);2:171- 8 .

5. Donly KJ and Sasa IS: Potential remineralization of post orthodontic 
demineralized enamel and the use of enamel microabrasion and bleaching for esthetics. Semin Orthod.( 2008);14:2205.

6. Boyde, J, . Neuman, W.F, and Hodge, H. C: On the mechanism of skeletal fixation of strontium. University of Rochester, Atomic Energy Project, (1958).No. UR 512: 1-16.

7. Thuy TT, Nakagaki $\mathrm{H}$ and Kato Ket al: Effect of strontium in combination with fluoride on enamel remineralization in vitro. Arch Oral Biol .(2008); 53(11): 1017-22.

8. Gedalia I, Yariv S, Brayer L, Greenbaum M :Strontium uptake by powdered and intact human root dentine. Arch Oral Biol .(1976); 21(7):413-6.

9. Marie JP: Effects of strontium on bone and bone cells. J. Trace Elements MedBiol. (1995); 9:227.

10.Jaffer, Oesterle, and Newman :Storage media effect on bond strength of orthodontic brackets.Am J Orthod Dentofacial Orthop (2009);136:83-6.

11. Maha Jamal AL Anni, Sulafa K. EL Samarrai, Balkees Taha Garib: Effect of Selected Metal Salts on the Microscopical Feature of Initial Carious - Like Lesion of Permanent Teeth. MDJ. (2010); 7:(2).

12.Artun J, Bergland S. Clinical trials with crystal growth conditioning as an alternative to acid-etch enamel pretreatment. Am

Orthod.(1984);85(4):333-340.

13.Jimenez EEO, Hilgenberg SP, Rastelli MC, Rsatelli MC, Pilatti GL, Orellana B, et al. Rebonding of unused brackets with different orthodontic adhesives. Dental Press J Orthod. (2012);17(2):69-76.
14. Attin R, Stawarczyk B, Keçik D, Knösel M, Wiechmann D, Attin T: Shear bond strength of brackets to demineralize enamel after different pretreatment methods. Angle Orthod. (2011); 82(1):56-61.

15.Featherstone JD, Stookey GK, Kaminski MA, Faller RV Recommendation for a non-animal alternative to rat caries testing Am J Dent (2011);24(5):289-294.

16.Featherstone JD, Mellberg JR. Relative rates of progress of artificial carious lesions in bovine, ovine and human enamel. Caries Res.( 1981);15:109-14.

17.Nakamichi I, Iwaku M, Fusayama T. Bovine teeth as possible substitutes in the adhesion test. J Dent Res. (1983);62: 1076-1081.

18.MARANHÃO Kalena de Melo et al. The effect of solutions on enamel of bovine teeth . Salusvita Bauru. (2009);28( 2):129-134.

19.Cristiane de Melo Alencar, Victor Feliz Pedrinha, Jesuína Lamartine Nogueira Araújo, Renata Antunes Esteves, Ana Daniela Silva da Silveira and Cecy Martins Silva :Effect of 10\% Strontium Chloride and 5\% Potassium Nitrate with Fluoride on Bleached Bovine Enamel .Open Dent J. (2017);11: 476-484.

20.Dedhiya MG, Young F, Higuchi WI. Mechanism for the retardation of the acid dissolution rate of hydroxyapatite by strontium. J Dent Res (1973);52:1097109.

21.Xiaojun D, Jing L, Xuehua G, Hong R Youcheng Y, Zhangyu G, et al. Effects of CPPACP paste on the shear bond 
strength of orthodontic brackets. The Angle Orthod. (2009);79(5):945-50.

22.Yin-Lin Wang, Hao-Hueng Chang, Yu-Chih Chiang, Chao-Hsiu Lin, ChunPin Lin: Strontium ion can significantly decrease enamel demineralization and prevent the enamel surface hardness loss in acidic environment. $\mathrm{J}$ Formos Med Assoc. (2018);118(1 Pt 1):39-49.

23. Reynolds IR: A review of direct orthodontic bonding. $\mathrm{Br} \mathrm{J}$ Orthod (1975);2:171- 8 . 